Rev. Elet. em Gestão, Educação e Tecnologia Ambiental (e-ISSN: 2236-1170)

\title{
PERCEPÇÃO DOS FUNCIONÁRIOS SOBRE A EDUCAÇÃO AMBIENTAL NAS ESCOLAS ESTADUAIS DO MUNICÍPIO DE SÃO GABRIEL-RS
}

\author{
Daniele Oliveira Freitas ${ }^{1}$, Ana Júlia Teixeira Senna², Ricardo Ribeiro Alves ${ }^{3}$ \\ ${ }^{1}$ Pós-Graduação Lato Sensu Educação: Interdisciplinaridade e Transversalidade, Universidade Federal do Pampa - \\ UNIPAMPA, Campus São Gabriel., dani_sg19@yahoo.com.br \\ 2 Engenheira Agrícola. Dra em Agronegócios. Professora Adjunta da Universidade Federal do Pampa (UNIPAMPA), \\ Campus São Gabriel. anasenna@unipampa.edu.br \\ ${ }^{3}$ Administrador. Doutor em Ciência Florestal. Professor Adjunto da Universidade Federal do Pampa (UNIPAMPA) - \\ Campus São Gabriel. ricardoalves@unipampa.edu.br
}

http://dx.doi.org/10.5902/223611706318

\section{RESUMO}

A educação ambiental é um instrumento essencial para consolidação de um paradigma sustentável. A educação é responsável pela disponibilização da informação e pela promoção da construção de conhecimentos. O objetivo deste trabalho é analisar a percepção dos funcionários das Escolas Estaduais de Ensino Fundamental, localizadas no Município de São Gabriel-RS, sobre a educação ambiental no seu ambiente de trabalho. Foram aplicados vinte e oito questionários in loco nas Escolas. Por meio dos resultados é possível constatar que na Escola A, todos os funcionários sabem o que são práticas de gestão ambiental e procuram sempre realizar estas práticas em seus domicílios. Em contrapartida, na Escola B existe coleta seletiva implantada, mesmo não havendo uma conscientização ambiental de toda a sua comunidade escolar.

Palavras chave: Contexto Escolar; Ensino Fundamental; Meio Ambiente.

\section{EMPLOYEES' PERCEPTION ON ENVIRONMENTAL EDUCATION IN STATE SCHOOLS IN THE MUNICIPALITY OF SÃO GABRIEL-RS}

\begin{abstract}
Environmental education is an essential tool for the consolidation of a sustainable paradigm. Education is responsible for furnishing information and for promoting the construction of knowledge. The goal of this paper is to analyze the perception of the employees of Elementary State Schools, located in the municipality of São Gabriel-RS, towards environmental education in their workplace. A total of 28 questionnaires were applied at the schools themselves. Through the results it is possible to ascertain that in School $A$, all the employees know what environmental management practices are and they always try to conduct these practices in their households. On the other hand, at School B, there is a selective garbage collection system in place, although the school community is not yet environmentally aware in its entirety.
\end{abstract}

Key words: School Context; Elementary School; Environment. 
Rev. Elet. em Gestão, Educação e Tecnologia Ambiental (e-ISSN: 2236-1170)

\section{INTRODUÇÃO}

A educação ambiental ainda é entendida por muitos apenas como a transmissão de conhecimentos ecológicos num enfoque disciplinar restrito. Como educação política, assume papel relevante na mudança da realidade, pois deve preparar o indivíduo para participar da resolução de problemas de sua comunidade.

A família e o ambiente escolar são importantes promotores da educação visando a preservação do meio ambiente. Para isso é necessário, mais do que informações e conceitos, que a escola se proponha a trabalhar com atitudes, formação de valores, e com ensino e aprendizagem de habilidades e procedimentos.

Diante da importância da questão ambiental para a sociedade, a proposta deste trabalho é analisar a percepção dos funcionários das escolas estaduais de ensino fundamental, localizadas no Município de São Gabriel-RS, sobre a educação ambiental no seu ambiente de trabalho.

\section{REFERENCIAL TEÓRICO}

\section{A Educação Ambiental no Contexto Familiar e Escolar}

A Educação Ambiental (EA) é hoje o instrumento eficaz para se criar e aplicar formas sustentáveis de interação entre a sociedade e a natureza. Segundo Vasconcellos (1997), a presença, em todas as práticas educativas, da reflexão sobre as relações dos seres entre si, do ser humano com ele mesmo e do ser humano com seus semelhantes é condição imprescindível para que a Educação Ambiental ocorra. Dentro desse contexto, conforme Dias (1992) as escolas destacam-se como espaços privilegiados na realização de atividades que propiciem essa reflexão, pois isso necessita de atividades de sala de aula e atividades de campo, com ações orientadas em projetos e em processos de participação que levem à autoconfiança, a atitudes positivas e ao comprometimento pessoal com a proteção ambiental implementados de modo interdisciplinar.

O desenvolvimento sustentável deve estar atrelado à educação ambiental. A família e os professores devem ser os introdutores e condutores da educação para preservar o meio ambiente e, a criança, desde cedo, deve aprender a cuidar da natureza. Na família e na escola é que se devem iniciar a conscientização e o cuidado com o meio ambiente natural.

Segundo os Parâmetros Curriculares Nacionais - PCNs (BRASIL, 1997), há a necessidade de trabalhar o tema Meio Ambiente no âmbito escolar, para possibilitar a formação de cidadãos conscientes, aptos para decidir e atuar no âmbito socioambiental, de forma engajada e comprometida com a vida e com o bem estar da sociedade. Mas, para que isso possa acontecer, a educação sobre o assunto deve ser trabalhada de forma a ir além de conceitos e formações, pois se deve buscar um trabalho voltado para a formação de atitudes e valores.

No momento em que o indivíduo cresce valorizando e respeitando o meio ambiente, fazendo com que essas ações façam parte dos seus valores e crenças, ele provavelmente repassará isso a sua família e assim sucessivamente. Comportamentos corretos são demonstrados na prática do dia-a-dia através de gestos de solidariedade, hábitos de higiene pessoal e dos diversos ambientes e participação em pequenas negociações.

A transversalidade propõe um tratamento inter-relacionado das diversas áreas de conhecimento, bem como uma conexão com as relações no âmbito da escola. Para Reigota (2006) estas novas atitudes devem ser desenvolvidas e exercitadas no ambiente escolar, em situações 
Rev. Elet. em Gestão, Educação e Tecnologia Ambiental (e-ISSN: 2236-1170)

reais, onde as mais diversas variáveis e conflitos apareçam e sejam trabalhadas em uma atividade democrática e dinâmica, atuando sistematicamente e progressivamente, de modo que o processo de educação aja sobre o ambiente, no ambiente e para o ambiente, correspondendo a uma atividade que abranja desde a informação e a vivência do problema, à mudança de comportamento. Desde 1997, com uma revisão dos currículos pelo MEC, os professores e especialistas em educação brasileiros obtiveram um instrumento oficial de orientação à implantação da EA nas escolas: os Parâmetros Curriculares Nacionais - PCNs (BRASIL, 1997).

Para os PCNs, a questão ambiental impõe a busca de novas maneiras de pensar e agir, individualmente e coletivamente, da sociedade frente aos modelos de produção de bens e suprimentos que garantem a sobrevivência da vida humana (BRASIL, 1997).

\section{Educação Ambiental em uma Abordagem Interdisciplinar}

A Educação Ambiental na sua condução de modo interdisciplinar é a chave para a mudança. O educador é o mediador da formação de cidadãos, dando clareza às ideias, articulando as reflexões e ele apresenta aquilo que os educandos não sabem e precisam saber. Dessa forma, o educador precisa se questionar quanto aos seguintes aspectos: Qual a relação que eu como educador quero com o que vou ensinar? Este é um ato de pensar diário, porque a cada novo assunto abordado é preciso planejar, exige determinação de quem o faz para decidir o que fazer como fazer, para que serve e quais as vantagens e desvantagens de realizar determinados trabalhos para atingir objetivos e obter resultados (Dalmás, 2008).

A Educação está passando por uma transformação que transcende a sala de aula e busca acompanhar a globalização. Vive-se a era da informação e da contextualização, nenhum aprendizado tem valor de forma isolada, nenhum conhecimento é pertinente se não for relacionado e "atravessado" por outros saberes (BRASIL, 1997). É nesse sentido que a interdisciplinaridade aparece como uma ferramenta fundamental para a Educação na perspectiva da formação de cidadãos integrados com o mundo.

De acordo com Dias (2000), a educação ambiental, por ser interdisciplinar, por lidar com a realidade, por adotar uma abordagem que considera todos os aspectos que compõem a questão ambiental (socioculturais, políticos, científico-tecnológicos, éticos, ecológicos, entre outros), por considerar que a escola não pode ser um agrupamento de gente trabalhando com outro amontoado de papel; por ser catalisadora de uma educação para a cidadania consciente, pode e deve ser o agente otimizador de novos processos educativos que conduzam as pessoas por caminhos em que se vislumbre a possibilidade de mudança e de melhoria do seu ambiente total e da qualidade da sua experiência.

Considerando essas questões, é necessário formar um sujeito consciente e capaz de efetuar mudanças, nas suas atitudes, de maneira a interferir positivamente no meio, com acesso à informação clara e objetiva para a formação de uma consciência crítica, capaz de levar as comunidades a se mobilizarem por um ambiente mais digno e saudável.

Fazenda (1979) reforça que a interdisciplinaridade é uma questão de atitudes do professor frente ao conhecimento e ao processo de ensino. Essa atitude pode ser expressa em habilidades para exercer trocas com os outros professores e integrar as disciplinas em projetos comuns. A abordagem interdisciplinar defende a superação da fragmentação do saber. A realização conjunta das atividades em diferentes áreas de estudo ou disciplinas e do esforço coletivo do corpo dirigente, docente e discente, associados à família e à comunidade, resultará em um trabalho interdisciplinar para o desenvolvimento da Educação Ambiental na escola. A 
Educação Ambiental é uma alternativa de ensino que oferece, à escola, uma grande chance de renovação.

\section{METODOLOGIA}

A presente pesquisa foi realizada em duas escolas estaduais, localizadas no município de São Gabriel-RS. Inicialmente foi feita a observação no ambiente escolar para verificar a existência de ações de educação ambiental nas escolas. Posteriormente, foi construído um instrumento de coleta de dados, contendo onze questões que abordaram o conhecimento dos funcionários sobre o que são práticas de gestão ambiental, se existe alguma prática de gestão ambiental ou algum programa relacionado ao meio ambiente em sua escola, se existe um programa de coleta seletiva em sua escola, quais as práticas os funcionários realizam para contribuir para a preservação do meio ambiente na escola, dentre outras.

Segundo Malhotra (2001), o questionário é uma técnica estruturada para a coleta de dados, que consiste em uma série de perguntas que um entrevistado deve responder. A elaboração de um questionário precisa atender a três objetivos específicos. Em primeiro lugar, o instrumento de coleta de dados deve traduzir a informação desejada em um conjunto de questões específicas que os entrevistados tenham condições de responder. Em segundo, precisa motivar e incentivar o entrevistado a cooperar com as informações demandadas. Por fim, em terceiro lugar, um questionário deve sempre buscar minimizar o erro na resposta.

Os questionários foram aplicados nos meses de dezembro de 2011 e janeiro de 2012, em duas escolas estaduais de ensino fundamental, localizadas na área urbana, no Município de São Gabriel, RS. A coleta de dados primários ocorreu da seguinte forma:

1) Contato prévio com os diretores das Escolas para obtenção de autorização para pesquisa;

2ㅇ) Os questionários foram aplicados in loco nas duas escolas e foram preenchidos pelos respondentes. Na Escola $\mathrm{A}$ foram entregues vinte e seis questionários a serem preenchidos por funcionários, dos quais se obtiveram retorno de doze questionários respondidos. Já na Escola $B$ foram entregues vinte e quatro questionários aos funcionários, com retorno de dezesseis questionários respondidos.

3) Os dados foram descritos e analisados e foram sistematizados em quadros.

A seguir serão apresentados os resultados dos questionários aplicados nas escolas.

\section{RESULTADOS E DISCUSSÃO}

As questões iniciais referiram-se às questões ambientais, como poluição e desmatamento. Em relação às questões ambientais, os funcionários foram perguntados se essas questões afetam o seu dia-a-dia.

Observa-se que os funcionários da Escola B mostram-se mais preocupados com as questões como poluição e desmatamento do que os funcionários da Escola A (Figura 1). 

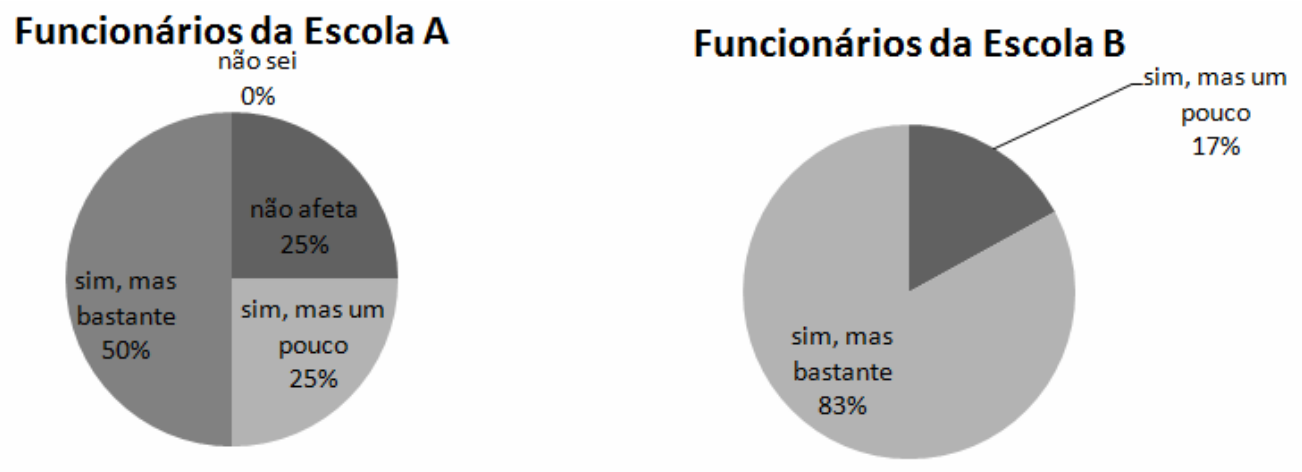

Figura 1. Porcentagem dos funcionários que afirmaram que questões como poluição e desmatamento afetam o seu dia-a-dia.

Afetando ou não o seu dia-a-dia, as questões ambientais como poluição e desmatamento fazem parte de suas preocupações? A Figura 2 ilustra as respostas dos funcionários das duas escolas.
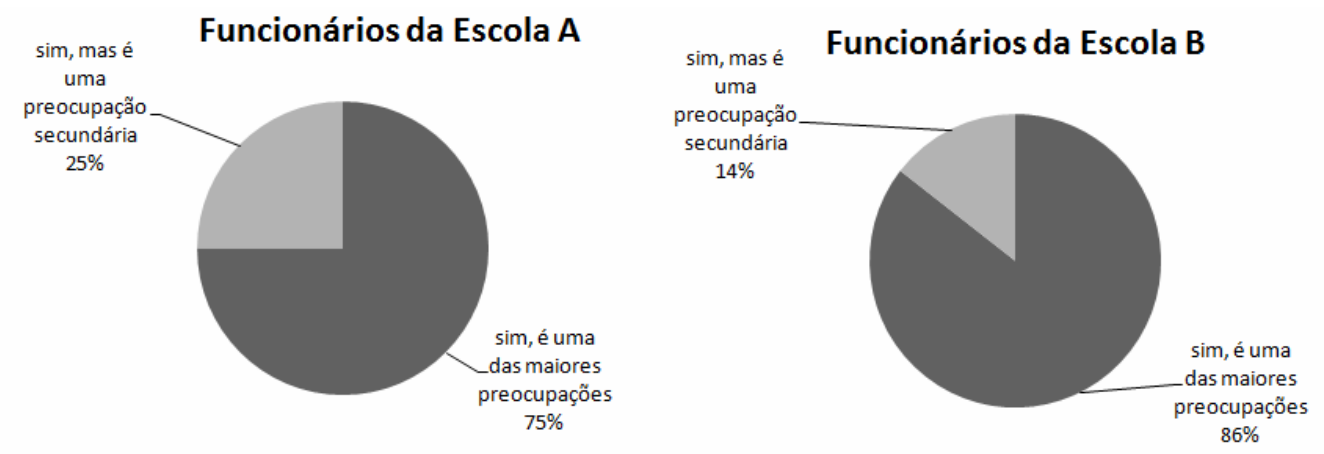

Figura 2. Porcentagem dos funcionários que se preocupam com a problemática ambiental.

Conforme ilustra a Figura 2, 86\% dos funcionários da Escola B salientaram que a questões ambientais, afetando ou não o seu dia-a-dia, fazem parte de suas preocupações. Já na Escola A, $75 \%$ dos funcionários entrevistados garantiram que às questões ambientais fazem parte de suas preocupações.

Na questão três foi perguntado aos funcionários se eles sabem o que são práticas de gestão ambiental, se realizam alguma prática em sua casa e, em caso afirmativo, quais as que mais realizam. A Figura 3 ilustra os resultados obtidos. 

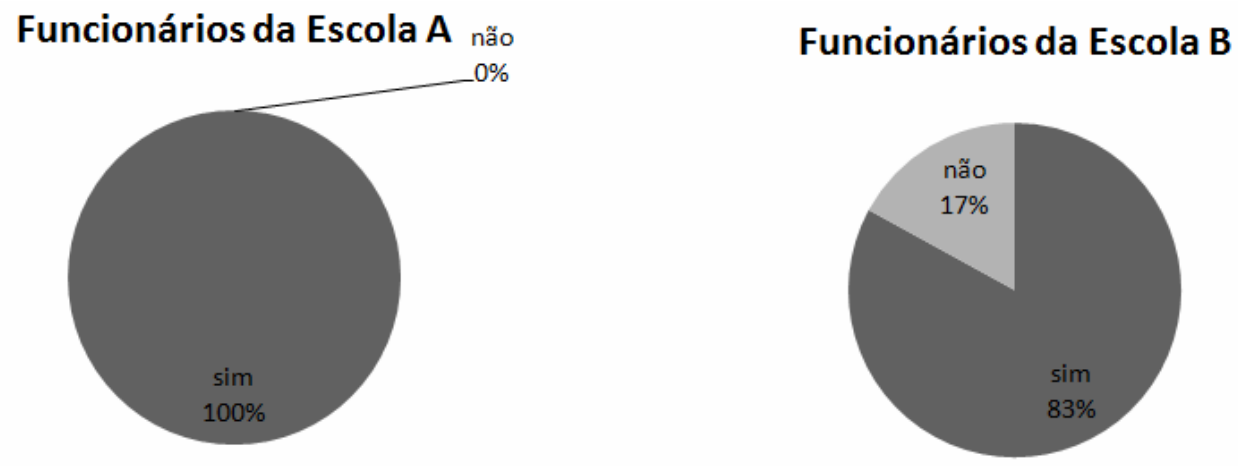

Figura 3. Porcentagem de funcionários que reconhecem o que são práticas de gestão ambiental.

Os funcionários da Escola $A$ reconhecem mais a o significado de práticas de gestão ambiental do que os funcionários da Escola B (Figura 3).

Na Escola $A$, segundo os funcionários, as principais práticas realizadas são: economia de energia; economia de água e coleta seletiva dos resíduos. Os funcionários da Escola B citaram economia de energia; economia de água e coleta seletiva dos resíduos.

$\mathrm{Na}$ questão seguinte os funcionários foram indagados quanto à existência de alguma prática de gestão ambiental ou algum programa relacionado ao meio ambiente em sua escola. $\mathrm{A}$ Figura 4 ilustra as respostas obtidas.

\section{Funcionários da Escola A}

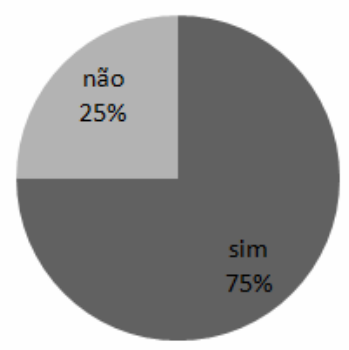

\section{Funcionários da Escola B}

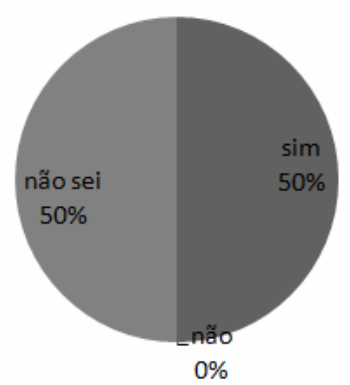

Figura 4. Porcentagem de funcionários que reconhecem alguma prática de gestão ambiental ou programa relacionado ao meio ambiente em sua escola.

Constata-se que $75 \%$ dos funcionários da Escola $A$ afirmaram que, no seu ambiente de trabalho escolar, existem práticas ou programas ambientais sendo desenvolvidos. Já na Escola B, apenas metade dos funcionários entrevistados reconhecem essas ações ambientais. Assim, conclui-se que os funcionários da Escola A visualizam práticas de gestão ambiental ou programas relacionados ao meio ambiente do que os funcionários da Escola B.

Outro aspecto avaliado foi se os funcionários das Escolas realizam práticas ambientais no seu dia-a-dia. A Figura 5 ilustra a realização das práticas ambientais pelos funcionários em suas casas. 


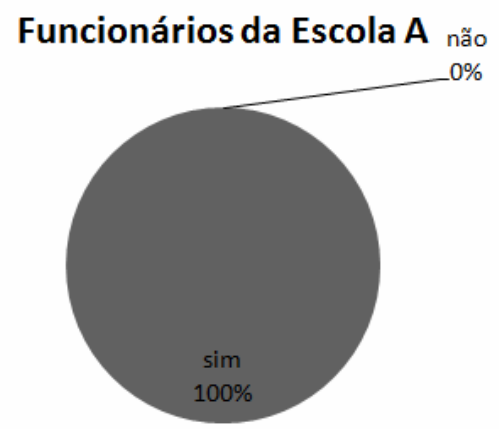

\section{Funcionários da Escola B}

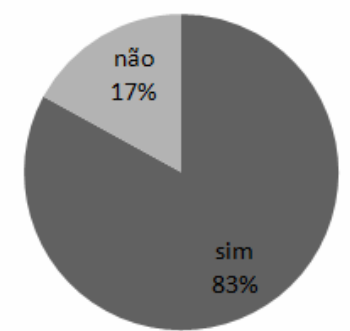

Figura 5. Porcentagem de funcionários que disseram realizar práticas ambientais em suas casas.

Verifica-se que, todos os funcionários da Escola $A$ conhecem o que são práticas de gestão ambiental (Figura 3) e as praticam em suas casas (Figura 5). Igualmente na Escola B, todos os funcionários que conhecem tais práticas efetivamente as realizam em suas residências. Tal fato evidencia que, quando há conhecimento por parte dos atores envolvidos, estes passam a incorporar as ações ambientais no seu dia-a-dia. Isso corrobora com a ideia de Dias (2000) que prega que a educação ambiental, por ser interdisciplinar, por lidar com a realidade, por considerar todas as esferas que envolvem a questão ambiental e por considerar que a escola não pode ser um agrupamento de pessoas trabalhando, pode e deve ser o agente otimizador de novos processos educativos que conduzam às pessoas a possibilidade de mudança e melhoria do seu ambiente. Nesse caso, conclui-se que foi a inserção da temática ambiental no ambiente escolar que delineou e reforçou o comportamento dos funcionários com as ações do cotidiano.

Na Escola A, as principais práticas realizadas são: economia de energia, economia de água, coleta seletiva dos resíduos, escolha de produtos com embalagens reduzidas. Já na Escola $\mathrm{B}$, as práticas mencionadas foram: economia de energia e de água, coleta seletiva dos resíduos, escolha de produtos com embalagens reduzidas sendo as mesmas práticas realizadas nas duas Escolas A e B por funcionários.

Todos os funcionários das Escolas A e B afirmaram conhecer o funcionamento do sistema de coleta seletiva. Posteriormente, os respondentes deveriam avaliar a existência do programa de coleta seletiva em sua escola.

A Figura 7 sintetiza as respostas.

\section{Funcionários da Escola $\mathrm{A}$}

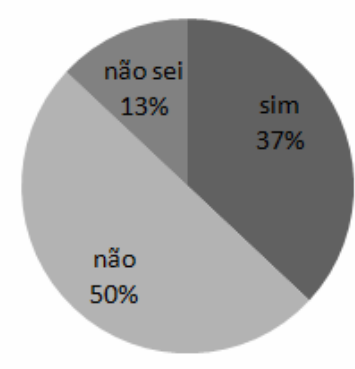

\section{Funcionários da Escola B}

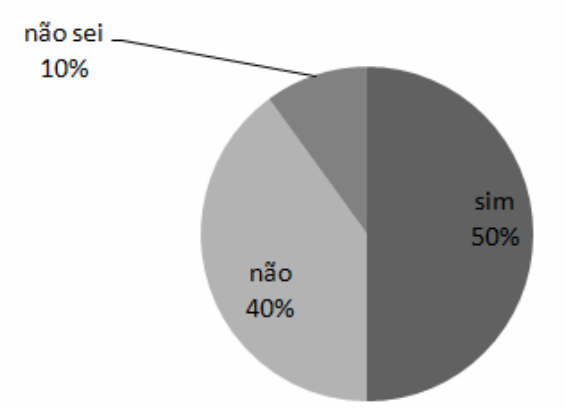

Figura 7. Porcentagem dos funcionários que reconhecem a existência de um programa de coleta seletiva em sua escola. 
Constata-se por meio da Figura 7 que os funcionários da Escola B reconhecem mais a existência do programa de coleta seletiva em sua escola do que os funcionários da Escola $A$.

O lixo e demais resíduos são jogados na lixeira da coleta seletiva? A Figura 8 ilustra a resposta dos entrevistados.
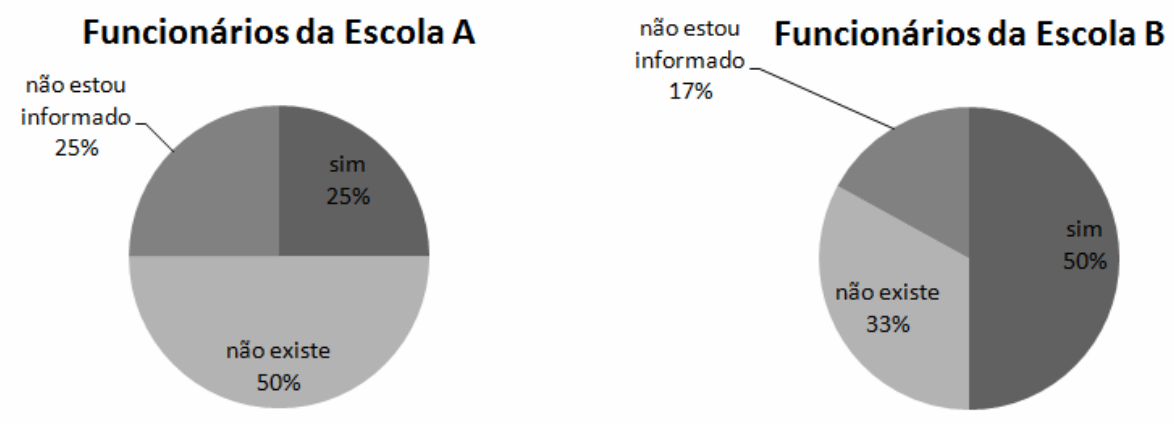

Figura 8. Porcentagem de funcionários que afirmaram depositar o lixo e os demais resíduos em coletores separados conforme a disposição.

Funcionários da Escola A

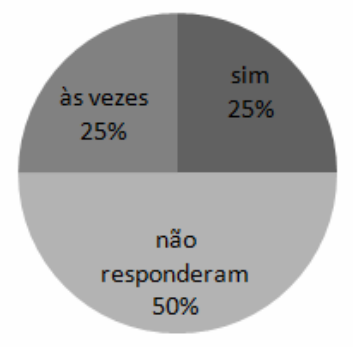

Funcionários da Escola B

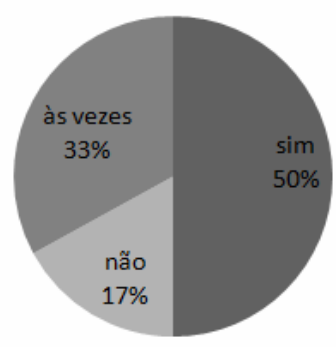

Figura 9. Porcentagem dos funcionários que descartam os resíduos corretamente.

Analisando a Figura 9, constata-se que a porcentagem de funcionários da Escola B que demonstram descartar os resíduos corretamente é superior a porcentagem de funcionários da Escola A. Isso demonstra que os funcionários da Escola B são mais conscientes quanto ao descarte correto de resíduos.

As principais práticas que os funcionários da Escola $A$ e $B$ executam para contribuir para a economia e preservação do meio ambiente são: evitar os desperdícios de energia elétrica, evitar o desperdício de água e realizar a separação de resíduos em lixeiras específicas, procurando contribuir para a coleta seletiva e preservação do meio ambiente.

Na questão posterior, foi avaliada a existência de algum material informativo de Educação Ambiental na sua escola. A Figura 10 sintetiza as respostas 
Funcionários da Escola $\mathrm{A}$

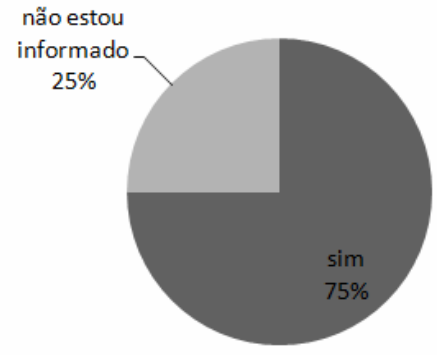

\section{Funcionários da Escola B}

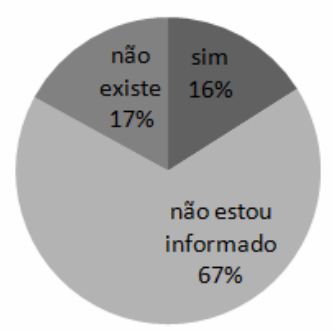

Figura 10. Porcentagem dos funcionários que conhecem algum material informativo de Educação Ambiental na sua escola.

Observa-se que a porcentagem de funcionários da Escola A que reconhecem a existência de algum material informativo de Educação Ambiental na sua escola é superior a porcentagem de funcionários da Escola $B$.

Nas Escolas A, os materiais informativos citados foram cartazes, painéis confeccionados pelos alunos e projetos e na Escola B os funcionários não citaram nenhum material informativo.

Por fim, foi solicitado aos respondentes que sugerissem melhorias nas ações de Educação Ambiental. Na Escola A, a principal sugestão foi o surgimento de mais projetos que buscam formar cidadãos conscientes do mundo que vivemos e educá-los para a conservação. Na Escola B foram sugeridas ações mais práticas como projetos envolvendo toda a comunidade escolar trabalhando a importância da preservação do meio ambiente.

A Figura 11 apresenta um resumo das respostas dos funcionários das escolas estaduais de ensino fundamental, sobre o seu conhecimento e as ações que estão contribuindo para a preservação do meio ambiente.

\section{Percepção dos Funcionários sobre a Educação Ambiental na Escola}

EEscola A (sim) Escola B (sim)

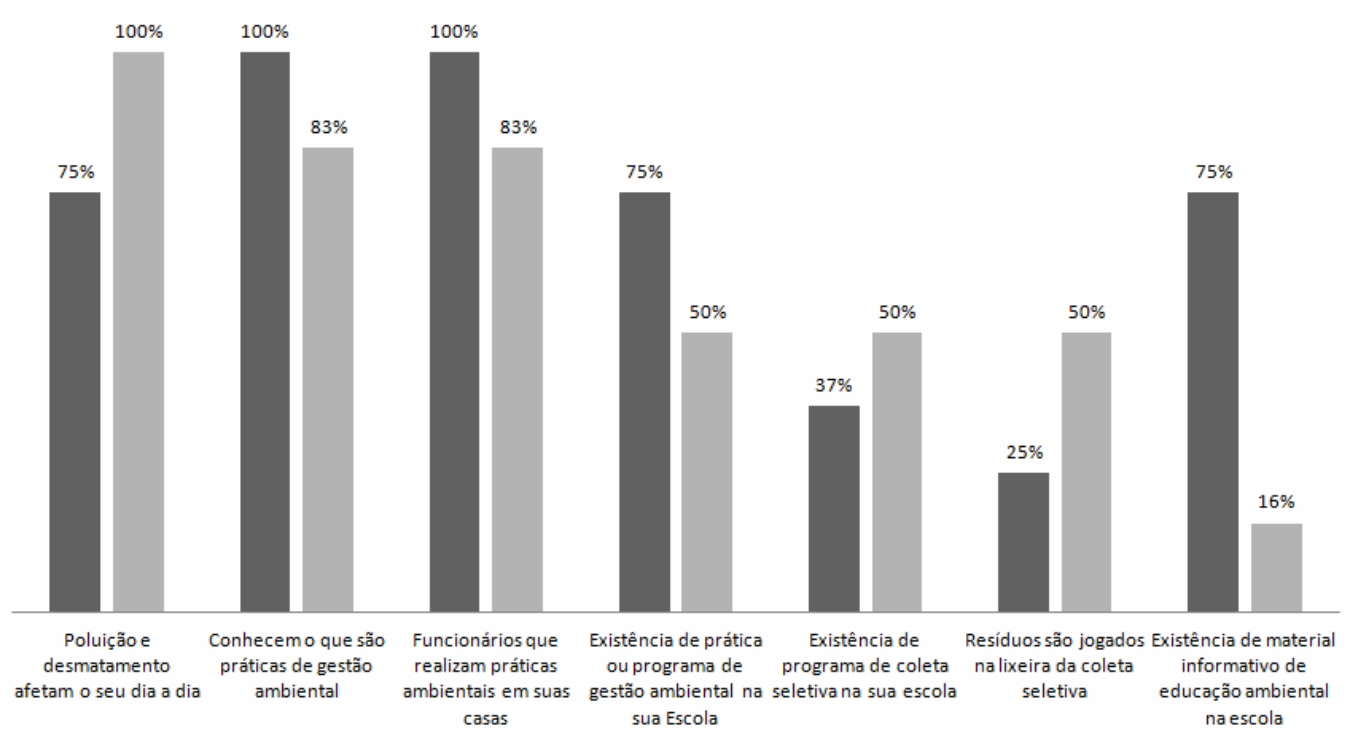

Figura 11. Percepção dos Funcionários sobre a Educação Ambiental nas duas Escolas Estaduais investigadas. 
De acordo com a Figura 11 é possível constatar que, os funcionários da Escola $A$, mostraram-se mais conscientes em relação às questões ambientais do que os funcionários da Escola B, pois os funcionários estão cientes do que são práticas de gestão ambiental e procuram sempre realizar estas práticas em seus domicílios. Porém, em contrapartida, na Escola $B$ existe coleta seletiva implantada, mesmo não havendo uma conscientização ambiental de toda a sua comunidade escolar.

\section{CONCLUSÕES}

A Educação Ambiental está inserida de diferentes formas e intensidades no ambiente escolar. A preocupação ambiental e a mudança comportamental voltada para o meio ambiente hoje são expressos na comunidade escolar, que compreende professores, gestores, alunos e funcionários.

A responsabilidade de conscientização sobre o meio ambiente deverá ser, também, preocupação da sociedade, pois nem sempre as pessoas têm acesso à educação formal, sala de aula. Portanto a responsabilidade, a preocupação com a natureza passa a ser da sociedade como um todo, não importa qual o seu papel na escola.

A Educação Ambiental é um meio de mobilizar a população para que adote um comportamento cotidiano que esteja alicerçado em valores de sustentabilidade econômica, social e cultural.

\section{REFERÊNCIAS BIBLIOGRÁFICAS}

BRASIL. Secretaria de Educação Fundamental. Parâmetros curriculares nacionais: introdução aos parâmetros curriculares nacionais / Secretaria de Educação Fundamental. Brasília: MEC/SEF, 1997.

DALMÁS, A. Planejamento Participativo na Escola. 14. ed. Petrópolis: Vozes, 2008.

DIAS, G. F. Educação Ambiental: Princípios e Práticas. São Paulo, Gaia, 1992.

DIAS, G.F. Educação Ambiental: Princípios e Práticas. 6 ed. São Paulo, Gaia, 2000.

FAZENDA, I.C.A. Integração e Interdisciplinaridade no Ensino Brasileiro. Efetividade ou Ideologia. São Paulo. Edições. Loyola, 1979.

MALHOTRA, N.K. Pesquisa de Marketing: Uma Orientação Aplicada. Porto Alegre: Bookman, 2001.

REIGOTA, M. O que é Educação Ambiental. 1 ed. São Paulo: Brasiliense, 2006.

VASCONCELLOS, H. S. R. A Pesquisa-Ação em Projetos de Educação Ambiental. In: PEDRINI, A. G. (org). Educação Ambiental: reflexões e práticas contemporâneas. Petrópolis, Vozes, 1997. 